\title{
CARCINOMA CON CÉLULAS GIGANTES TIPO OSTEOCLASTO DE VEJIGA. UN CASO DE RARA PRESENTACIÓN. REVISIÓN DE LA LITERATURA
}

\author{
F. GARCÍA GARCÍA, J. GARCÍA LIGERO, F. MARTÍNEZ DÍAZ*, J.L. RICO GALIANO, \\ M. TOMÁS ROS, A. SEMPERE GUTIÉRREZ, J.P. MORGA EGEA, J.V. PÉREZ CARRIÓ**, \\ L.O. FONTANA COMPIANO
}

\begin{abstract}
Servicio de Urología. *Servicio de Anatomía Patológica. ***Servicio de Radiología. Hospital General
\end{abstract} Universitario de Murcia. Murcia.

Actas Urol Esp. 27 (4): 317-320, 2003

\section{RESUMEN}

"CARCINOMA CON CÉLULAS GIGANTES TIPO OSTEOCLASTO DE VEJIGA. UN CASO DE RARA PRESENTACIÓN. REVISIÓN DE LA LITERATURA"

Presentamos un caso de tumor vesical con diferenciación pseudosarcomatosa del estroma.

Son extremadamente raros (sólo se había descrito 78 casos en el mundo hasta el año 2001). También son llamados carcinosarcomas heterólogos, dentro de los cuales se encuentran los llamados carcinosarcomas con células gigantes tipo osteoclasto, que se caracterizan por ser positivos para vimentina y fosfatasa ácida y negativos para marcadores epiteliales (citoqueratinas de bajo peso y lisozima).

PALABRAS CLAVE: Carcinosarcoma heterólogo. Diferenciación estromal pseudosarcomatosa. Células tipo osteoclasto.

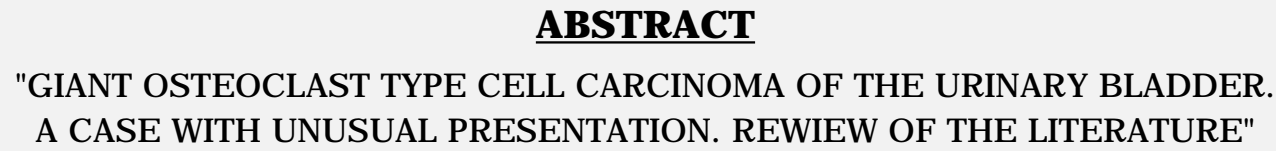

We report a case of neoplasm of the urinary bladder with pseudosarcomatous stromal differentiation. Heterologous carcinosarcomas are extremly rare malignant neoplasms (seventy-eight cases have been previonsly described).

This is a case of carcinoma containing numerous osteoclast type giant cells that stained for vinmentin and acid phosphatose and were negative for cytokeratin and lysozyme.

KEY WORDS: Heterologous carcinosarcoma. Sarcomatous stromal differentiation. Osteoclast type giant cells.

$\mathrm{D}$ entro de los tumores vesicales malignos los más frecuentes son los carcinomas uroteliales o carcinomas de células transicionales que representan el $80-90 \%{ }^{1}$; la mayor parte son papilares (70\%), y el resto presentan fusión de las papilas e incluso masas sólidas, correspondiendo a las formas más agresivas ${ }^{2}$. Entre estos tumores últimos cabe destacar los de células fusiformes o fusocelular, el carcinoma indiferenciado y el carcinoma con diferenciación pseudosarcomatosa del estroma ${ }^{3}$, que es el caso que nos ocupa; estos tumores con diferenciación pseudosarcomatosa del estroma se caracterizan por ser positivos para vinmentina y fosfatasa ácida y negativos para marcadores epiteliales (citoqueratinas de bajo peso y lisozima). 


\section{CASO CLÍNICO}

Se trata de un paciente de 70 años con antecedentes de intolerancia hidrocarbonada y osteoporosis secundarias a tratamiento esteroideo por EPOC tipo bronquitis crónica y antecedentes de hábito tabáquico importante, con múltiples ingresos por descompensación y sobreinfección respiratoria (algún episodio por pseudomona fluorescens).

En un ingreso por descompensación de su enfermedad respiratoria y en el contexto de un síndrome miccional obstructivo por el que era revisado y tratado en consultas externas de Urología, presentó episodio de hematuria macroscópica con coágulos con polaquiuria y disuria, realizándose ecografía que mostró crecimiento endoluminal vesical, compatible con neoplasia vesical (Fig. 1).

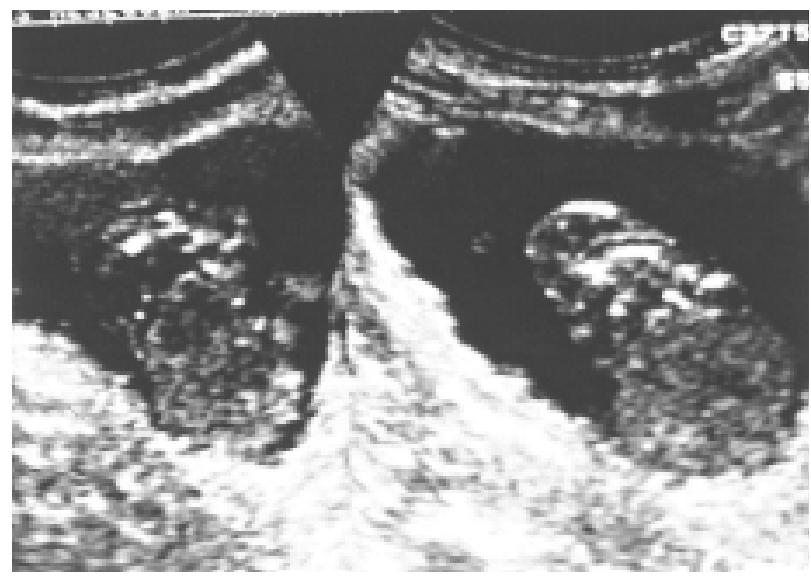

FIGURA 1. Ecografia sugestiva de tumor vesical.

Se realizó RTU de tumoración de aspecto sólido situado sobre pared lateral derecha, junto a meato ureteral izquierdo de $1 \mathrm{~cm}$ de diámetro aproximado y con resultado en el estudio anatomopatológico de carcinosarcoma heterólogo, con afectación de la muscular (estadio B de JewettMarshall). A pesar del diagnóstico anatomopatológico de carcinoma urotelial infiltrante se desestimó la cistectomía radical por contraindicación de anestesia general por sus problemas respiratorios.

Cuatro meses después de esta primera resección transuretral, el paciente presentó nuevo episodio de hematuria, realizándose nuevas pruebas complementarias (ecografia, cistoscopia) (Fig. 2), que mostraron recidiva de tumor vesical de unos $3 \mathrm{~cm}$ de diámetro situado sobre pared lateral derecha-trígono de aspecto sólido, que se resecó nue-

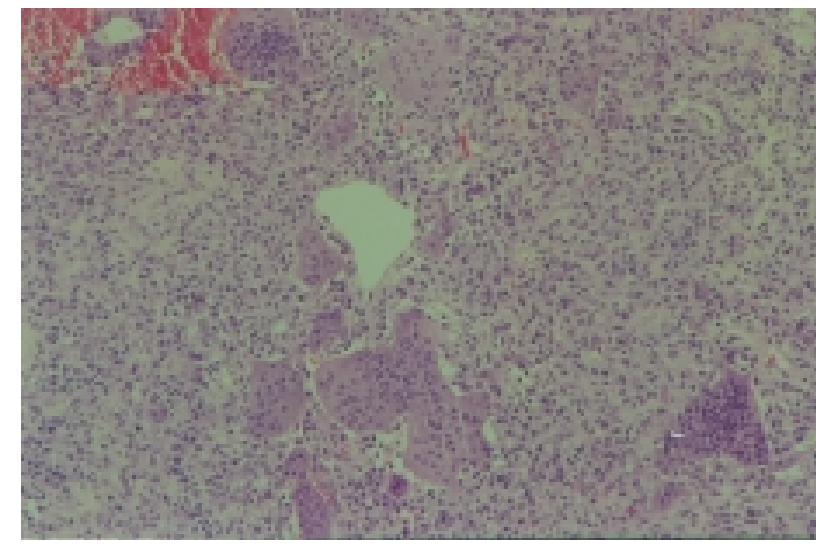

FIGURA 2. Carcinosarcoma con células gigantes tipo osteoclasto.

vamente con resultado en el estudio anatomopatológico de tumor con diferenciación pseudosarcomatosa del estroma y células multinucleadas gigantes tipo osteoclasto con producción de material osteoide (Figs. 3, 4 y 5).

En el post-operatorio, el paciente presentó insuficiencia respiratoria grave que precisó maniobras de reanimación cardiopulmonar; la evolución posterior fue satisfactoria, siendo dado de alta tras quedar asintomático.

Dos meses después, ante nuevos episodios de hematuria importante con disuria y polaquiuria, precisando sondaje vesical por episodio de reducción aguda obstructiva del flujo urinario, fue necesario ingresar al paciente, y al no controlar la hematuria, intervenirlo con anestesia general pese a sus problemas respiratorios, realizándose cistoprostactectomía radical y derivación urinaria no continente tipo Bricker.

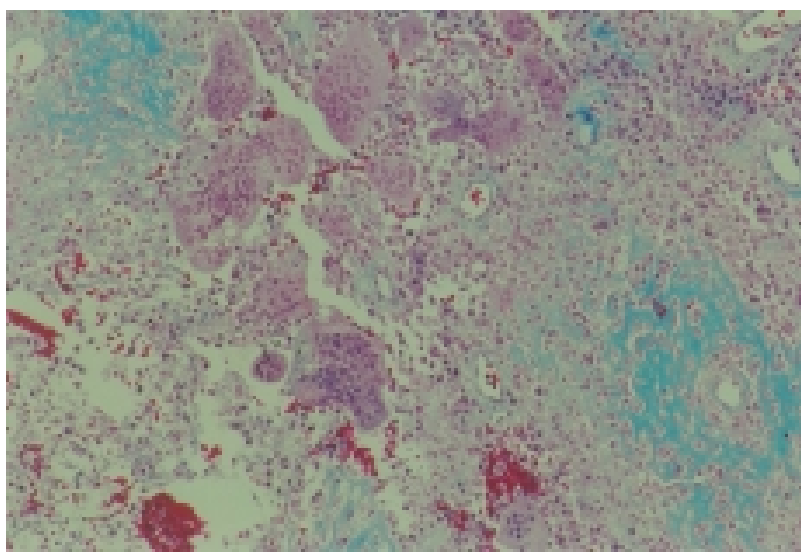

FIGURA 3. Tinción con tricrómico de Mason. 


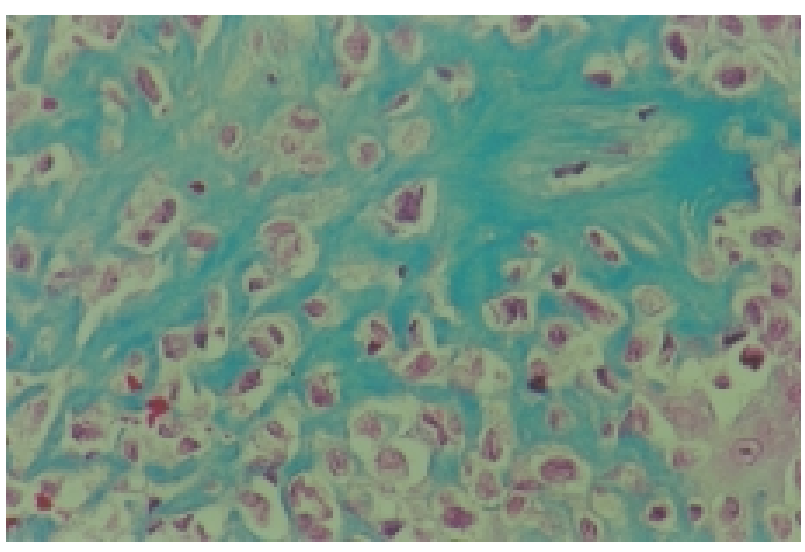

FIGURA 4. Detalle de material osteoide.

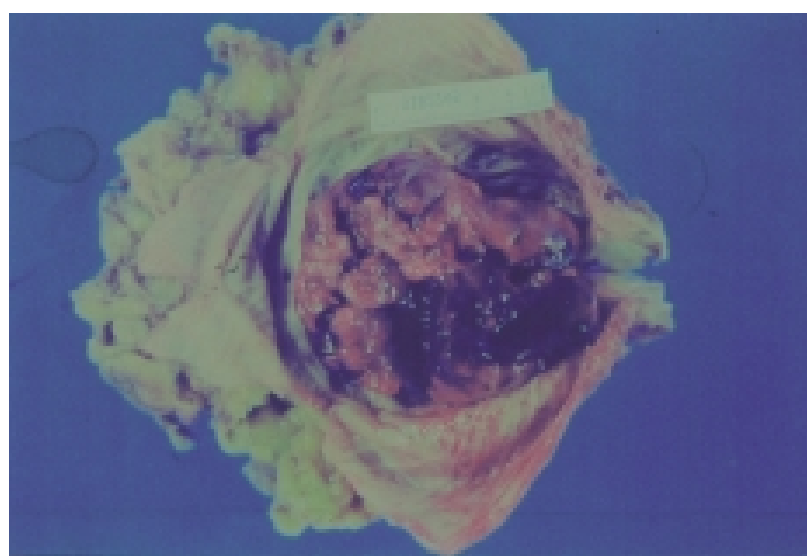

FIGURA 5. Pieza macroscópica de cistectomia radical.

Aunque la situación clínica posterior general fue buena, 14 días después de ser intervenido, presentó suboclusión intestinal, sepsis y fracaso multiorgánico, falleciendo finalmente.

\section{COMENTARIO}

Aproximadamente el 80\% de los tumores vesicales malignos son carcinomas de células transicionales, pero hay un $15-20 \%$ que son carcinomas no uroteliales (epidermoide, adenocarcinoma, adenoescamoso), linfomas, mesenquimales (leiomiosarcoma, sarcoma, etc.) o metastásicos (fundamentalmente de mama, estómago, intestino, páncreas, útero, riñón y próstata 4 .

Dentro de los carcinomas transicionales el $70 \%$ son papilares y el resto presentan fusión de papilas o masas sólidas, siendo más agresi$\operatorname{vos}^{1,2}$.
En el grupo de carcinomas transicionales no papilares podemos destacar los de células fusiformes, que se consideran mal diferenciados, a los que se llama también sarcomatoides y que presentan característicamente zonas de células elongadas entremezcladas con células gigantes. Tienen citoplasma eosinófilo y expresan positividad para citoqueratinas, ocasionalmente vimentina y negatividad para desmina.

Otro grupo dentro de los carcinomas uroteliales no papilares son los carcinomas indiferenciados, y otro grupo son los carcinomas con diferenciación pseudosarcomatosa del estroma. En estos últimos se induce un fenómeno reactivo, adquiriendo el estroma un aspecto pseudosarcomatoso y expresan positividad para vimentina y negatividad para citoqueratinas y desmina ${ }^{2}$. Hay posibilidad de encontrar células tipo osteoclasto, llamándoseles en ocasiones osteoclastomas ${ }^{5}$, soliendo ocurrir en estos casos necrosis y hemorragia ${ }^{6}$. Se han publicado 19 casos de metaplasia ósea estromal, y también puede estar asociada a metaplasia condroide que se puede ver en las metástasis ${ }^{7,8}$.

Así pues, dentro de los carcinomas con diferenciación pseudosarcomatosa del estroma que son extremadamente $\operatorname{raros}^{9,10}$ (sólo se había descrito 78 casos hasta $2001^{11}$ ), también llamados carcinosarcomas heterólogos, se encuentran los llamados carcinosarcomas con células gigantes tipo osteoclasto, que se caracterizan por ser positivos para vinmentina y fosfatasa ácida ${ }^{12,13}$ y negativos para marcadores epiteliales.

\section{REFERENCIAS}

1. OLSSON CA, WHITE RW.: Cancer of the bladder, en: principles and management of urologic cancer. Javadpour N, editor. Editorial Williams and Wilkins 1979: 337. Baltimore.

2. ALGABA F, MORENO A, TRIAS I.: Uropatulogía tumoral. Pulso Ediciones 1996: 112-123.

3. YOUNG RH, WICK MR.: Transitional cell carcinoma of the urinary bladder with pseudosarcomatous stroma. Am J Clin Pathol 1988; 89: 216.

4. EBLE JN, YOUNG RH.: Carcinoma of the urinary bladder: a review of its diverse morphology. Semin Diagn Pathol 1997 may; 14 (2): 98-108.

5. BORG-GRECH A, MORRIS JA, EYDEN BP.: Malignant osteoclastoma-like giant cell tumor of the renal pelvis. Histopathology 1987; 11: 415.

6. MING WJ, BERSANI L, MANTOVANI A.: Tumor necrosis factor is chemotactic for monocytes and polymorphonuclear leukocytes. J Immunol 1987; 138: 1469. 
7. EBLE JN, YOUNG RH.: Stromal osseus metaplasia in carcinoma of the bladder. J Urol 1991: 145: 823.

8. LAM KY.: Condroid and osseus metaplasia in carcinoma of the bladder. Report of two cases and rewiew of the literature. J Urol Pathol 1995; 3: 255.

9. PERRET L, CHAUBERT P, HESSLER D.: Primary heterologous carcinosarcoma (metaplastic carcinoma) of the urinary bladder: a clinicopatohologic, immunohistochemical, and ultranstructural analysis of eight cases and review of the literature. Cancer 1998 apr. 15; 82 (8): 1535-1549.

10. IKEGAMI H, IWASAKI HY.: Sarcomatoid carcinoma of the urinary bladder: a clinicopathologic and immunohistochemical analysis of 14 patients. Hum Pathol 2000 mar; 31 (3): 332-340.

11. BASCHINSKY DY, CHEN JH, VADMAL MS.: Carcinosarcina of the urinary bladder - an aggresive tumor with diverse histogenesis. A clinicopatho- logic study of 4 cases an review of the literature. Arch Pathol Lab Med 2000 aug; 124 (8): 1172-1178.

12. ZUCKERBERG LR, ARMIN AR, PISHARODI L, YOUNG RH.: Transitional all carcinoma of the urinary bladder with osteoclast-type giant cells: a report of two cases and review of the literature. Histopathology 1990 nov; 17 (5): 407-411.

13. AMIR G, ROSENMANN E.: Osteoclast -like giant cell tumour of the urinary bladder. Histopathology 1990 nov; 17 (5): 413-418.

Dr. F. García García

Urbanización la Basílica, Dúplex 21

30157 Algezares (Murcia)

(Trabajo recibido el 1 abril de 2002) 